Article

\title{
Urban Planning by Experiment at Precinct Scale: Embracing Complexity, Ambiguity, and Multiplicity
}

\author{
Darren Sharp * and Rob Raven \\ Monash Sustainable Development Institute, Monash University, Clayton, VIC 3800, Australia; \\ E-Mails: darren.sharp@monash.edu (D.S.), rob.raven@monash.edu (R.R.) \\ * Corresponding author
}

Submitted: 31 July 2020 | Accepted: 27 October 2020 | Published: 26 March 2021

\begin{abstract}
Urban living labs have emerged as spatially embedded arenas for governing urban transformation, where heterogenous actor configurations experiment with new practices, institutions, and infrastructures. This article observes a nascent shift towards experimentation at the precinct scale and responds to a need to further investigate relevant processes in urban experimentation at this scale, and identifies particular challenges for urban planning. We tentatively conceptualise precincts as spatially bounded urban environments loosely delineated by a particular combination of social or economic activity. Our methodology involves an interpretive systematic literature review of urban experimentation and urban living labs at precinct scale, along with an empirical illustration of the Net Zero Initiative at Monash University in Melbourne, Australia, which is operationalising its main campus into a living lab focussed on precinct-scale decarbonisation. We identify four processual categories relevant to precinct-scale experimentation: embedding, framing, governing, and learning. We use the empirical illustration to discuss the relevance of these processes, refine findings from the literature review and conclude with a discussion on the implications of our article for future scholarship on urban planning by experiment at precinct scale.
\end{abstract}

\section{Keywords}

experimentation; governance; net zero; precinct; urban living labs; urban planning

\section{Issue}

This article is part of the issue "Urban Planning by Experiment" edited by Christian Scholl (Maastricht University, The Netherlands) and Joop de Kraker (Maastricht University, The Netherlands).

(C) 2021 by the authors; licensee Cogitatio (Lisbon, Portugal). This article is licensed under a Creative Commons Attribution 4.0 International License (CC BY).

\section{Introduction}

Reports of cities aiming to reach net zero targets by 2050 or before are increasingly heard in global climate discourse. According to the United Nations Framework Convention on Climate Change's (2020) Race to Zero, in 2020 more than 450 cities have committed to net zero targets. Arguably, such ambitions will require major transformations in urban infrastructures, institutions, and behaviours that move well beyond business-as-usual. Planning tools such as scenarios, land use controls, regulatory standards, and design overlays are very useful but less effective in situations of high complexity, deep uncertainty, and ambiguity about the future, as they rely on assumptions and conditions to be reliably known and predictable. Radical sustainability ambitions such as net zero cities have never been realised, which suggest the need for different approaches that are more explorative, adaptive, learning-based, and evolutionary in nature. Experimentation is a key approach that cities globally have embraced to navigate such complex and ambiguous contexts, yet it remains often at the fringes of mainstream urban planning scholarship and practice (Honey-Rosés, 2019; Nyseth, Ringholm, \& Agger, 2019). The net result is that mainstream urban planning still largely operates within a 'predict and provide' paradigm that is incapable of overcoming deep unsustainability.

Experimentation has been a focal point of transition studies scholarship in relation to grassroots 
innovations (Seyfang \& Smith, 2007), reflexive governance (Kemp \& Loorbach, 2006), path-breaking innovation (Smith \& Raven, 2012), and sustainable development (van den Bosch, 2010). City governments and other urban actors have increasingly started to integrate experimental approaches such as 'urban experiments' or 'urban living labs' in their planning portfolios. In academic writing, living labs have been explored as multi-actor arenas for experimentation that utilise processes of social learning and participant co-creation for socio-technical innovation at the local scale (Liedtke, Welfens, Rohn, \& Nordmann, 2012; Puerari et al., 2018). Urban living labs have been conceptualised as spatially embedded arenas for experimentation where new practices and infrastructures are tested and operationalised in diverse forms ranging from emerging, grassroots initiatives to large-scale, planned, and corporate-led projects across multiple cities (Bulkeley et al., 2016; Evans, Karvonen, \& Raven, 2016; Voytenko, McCormick, Evans, \& Schliwa, 2016). Some contributions use 'transition management' as a process-oriented approach to mobilise and empower city stakeholders in reflexive urban governance experiments (Nevens, Frantzeskaki, Gorissen, \& Loorbach, 2013). Others argue more generally that urban living labs enable participants to design, test, and learn in real-world contexts (McLean, Bulkeley, \& Crang, 2016; von Wirth, Fuenfschilling, Frantzeskaki, \& Coenen, 2019). Scholarly work has also started to report and reflect on the challenges and limitations of such approaches from various perspectives (Evans \& Karvonen, 2014).

Ambitions for urban living labs are beginning to appear at a precinct scale (or related scales such as district or neighbourhood; Marvin, Bulkeley, Mai, McCormick, \& Palgan, 2018). We tentatively conceptualise precincts as spatially bounded urban environments loosely delineated by a particular (combination of) social or economic activity, such as a university precinct, a retail precinct, a technology precinct, or a residential precinct, but also mixed precincts that combine business, residential, entertainment, and dining functions, for instance. From an urban planning perspective, the precinct scale represents a functional scale at which the planning and construction of infrastructure is routinely organised. For instance, a residential precinct requires different kinds of transport, energy, and building infrastructures than a technology precinct.

In the context of net zero transitions, we observe nascent interest from urban actors to move beyond the scale of individual buildings or sectorally-bounded infrastructures to articulate precinct-scale ambitions for net zero futures.

Our proposition here is that experimentation at the precinct scale indeed offers an appropriate scale for urban planning experimentation, but this requires key processes to operate beyond one-off initiatives and projects through 'aggregation activities' that build over time (Geels \& Raven, 2006). In a similar vein, emerg- ing debates on 'portfolios of experiments' (Torrens \& von Wirth, 2020) point towards the need to explore the enabling conditions and processes across multiple experiments and domains and across time-frames that go beyond those of single, 'projectified' experiments. While relatively much is known about the conditions and processes within experimentation, taking a longer-term, multi-initiative, and multi-domain perspective increases complexities and ambiguities in the governance of experimentation. As such, we believe that urban planning by experiment at the precinct scale has the potential to deliver integrative urban transformation, yet acknowledge that the processes and challenges related to precinct scale urban experimentation remain under-researched and under-articulated.

The aim of this article is to identify what are likely to be relevant conditions and processes in urban experimentation at the precinct scale, identify the particular challenges at this scale for urban planning, as well as suggest important knowledge gaps that can inform a future planning research and practice agenda. This article responds to the following research question: What are the relevant processes, challenges, and future research implications for precinct-scale urban experimentation?

This article is structured as follows. In Section 2 we describe our methodology and provide an overview of the empirical illustration of the Net Zero Initiative (NZI), at Monash University in Melbourne, Australia, which is decarbonising its domestic campuses and operationalising its main campus into a precinct-scale living lab. In Section 3 we present the results of our literature review of urban living labs through a precinct-scale lens by analysing key processes of experimentation: embedding, framing, governing, and learning. We use the empirical illustration to discuss the relevance and refine findings from the literature review. In Section 4 we discuss the implications of our article for future scholarship on urban planning by experiment at precinct scale and present a short conclusion.

\section{Methodology}

We explored urban experimentation and urban living labs at precinct scale following an interpretive systematic literature review. The academic literature was extracted following a thorough, scientifically robust, and transparent methodology. A qualitative-style, interpretative approach was utilised due to the broad applicability of the subject area, with iterative refinement needed, as interrelated concepts were uncovered in the literature. Our analysis suggests the types of challenges that may occur at this scale for urban planning by experiment. Our analytical scheme is tentative and intended to generate future propositions and empirical verification, as the practice and research on the deliberate planning, design, and enactment of precinct-scale experimentation is still early-stage. Hence, we acknowledge that the results of our literature review are predominantly 
based on research on urban experimentation that did not explicitly take a precinct-scale perspective. Our systematic review is therefore developed with a perspective to not only generate a state-of-the-art understanding of potentially relevant processes for precinct-scale experimentation, but also inform a future research and practice agenda deliberately concerned with precinct-scale experimentation. We return to this in the discussion section.

First, we performed a search for articles in Scopus, one of the major bibliometric abstract and citation databases of peer-reviewed academic publications. We selected Scopus due to its larger journal coverage despite its bias towards Natural Sciences over Social Sciences (Mongeon \& Paul-Hus, 2016). A language specification was applied, with all articles being included in the review process being written in English. No restriction was applied to date of publication. Key words were selected to capture various permutations of living lab experimentation at the appropriate scale: ("living lab" OR "living laboratory" OR experiment OR experimentation) AND (transition OR transformation OR planning) AND (socio-technical OR sustainability) AND (urban OR precinct $O R$ district $O R$ neighbourhood $O R$ neighborhood). The search terms were chosen based on our framing of the study on urban planning by experiment at precinct scale. We limited our search string primarily to cover the sustainability transitions and urban studies literatures where research on urban experimentation has been most thriving. The key words needed to appear in titles or keywords or abstracts. This search string yielded 325 articles.

Next, we extracted basic data from the Scopus search including title, author/s, abstract, year published, journal, and tags. This data was exported as a RIS file and imported into Covidence, the systematic review management platform. The abstracts were then screened for relevance in Covidence based on explicit reference to real-world experimentation or urban living labs at the precinct, district, test-bed, or neighbourhood scale. We excluded articles that made no reference to experimentation or living labs, or did not appear to have any explicit implications for urban planning given that our study is explicitly focused on urban planning by experiment. After abstract screening, we were left with 90 articles on the subject of urban living labs that matched our inclusion criteria. Using our own assessment, we identified additional prominent articles about experimentation and urban living labs, which were not found by the protocol-driven search of the Scopus database. All articles were read in full and we used a manual conceptdriven coding approach to extract data that appeared in the included articles. 19 articles did not contain relevant or significant findings or meet the inclusion criteria on full reading and these do not appear in the results section. We coded for themes related to processes of experimentation at precinct scale and urban experimentation more broadly. During coding, and based on our own understanding of intellectual roots and develop- ments in this literature, we identified prominent themes to describe key processes of experimentation.

Through an iterative process of reading, preliminary categorisation, testing tentative categories with our own observations in our empirical illustration, and further analytical refinements, we attempted to achieve methodological rigour and robustness as best as possible, taking into consideration the emergent and explorative nature of the research question and empirical phenomenon (Grodal, Anteby, \& Holm, 2020). Through our literature review of urban living labs in geographically distinct areas like 'precincts' (Wiktorowicz et al., 2018), 'districts' (Martin et al., 2019), 'test-beds' (Levenda, 2018), or 'neighbourhoods' (Audet, Segers, \& Manon, 2019), we identified four processual categories relevant to precinct-scale experimentation: embedding, framing, governing, and learning (see for similar approaches to categorisation, for instance, Bulkeley et al., 2016; Geels \& Raven, 2006; Kemp, Schot, \& Hoogma, 1998; Kiss et al., 2020). We specifically searched for data related to challenges for experimentation at precinct scale. We use these conceptual categories to explore how experimentation unfolds at the precinct scale.

In addition to the literature review we have used Monash University's NZI as an empirical illustration to refine our conceptual and literature-driven analytical procedures. For the illustration, we relied on selective policy documents and grey literature, and ongoing involvement in operationalising the urban living lab in question. This is not a conventional case study as its purpose is to illustrate some of the conceptual findings from the review, but not to test them. The illustration is not based on systematically collecting and reviewing all relevant materials, but on a selective engagement and participation with the initiative. Hence, this article's results are, from a methodological perspective, only resting on the interpretive systematic literature review. We introduce the empirical illustration below.

\subsection{NZI Empirical Illustration}

Monash University is the largest in Australia and a significant consumer of energy, with more than 70,000 student enrolments and over 150 buildings spread across its domestic campuses. The NZI is a $\$ 135 \mathrm{M}$ program that is transforming Monash University's four Australian campuses to become net zero in terms of carbon emissions by 2030, in line with the Paris Agreement targets. Monash University is using its campuses as a living lab with a primary focus on its main campus in Clayton (Metropolitan Melbourne), to research, develop, and implement the NZI through a range of socio-technical innovations, with a view of both learning-how-to-do organisational decarbonisation and with an ambition to shape best practice in the transition towards net zero emissions locally and internationally.

The NZI program includes a range of measures including energy efficiency upgrades such as LEDs, 
high-performing building facades, and more efficient appliances. Campus electrification is occurring through replacement of gas boilers with electric heat pumps and building thermal precincts to more efficiently provide heating and cooling. Thousands of solar panels have been installed and a renewable energy power purchase agreement has been signed to buy rights to electricity and large-scale renewable energy certificates generated by a local wind farm (Monash University, 2018). An on-site $100 \%$ renewable electricity microgrid, including $1 \mathrm{MWh}$ of battery storage, has been commissioned as a real-world demonstration of a transactive energy market solution (Khorasany, Azuatalam, Glasgow, Liebman, \& Razzaghi, 2020).

The NZI is envisioned to be replicated in other universities and organisations within and beyond the local precinct level. The NZI provides the opportunity to research how new technologies, governance arrangements, policies, business models, and behavioural interventions can be translated and scaled to accelerate urban decarbonisation efforts through socio-technical innovations deployed on site. We use the tentative results from the literature review to reflect on, and explore their relevance for understanding how, key processes of experimentation are being carried out as the NZI moves from its foundational activities focussed on capital investment in renewable infrastructure to broaden its focus and incorporate research activities through the establishment of a precinct-scale living lab situated in the broader 'Monash Technology Precinct' (MTP). In the next section we refer to the NZI in four text boxes through our lens of precinct-scale processes.

\section{Results: Urban Living Labs at Precinct Scale-An Overview}

Urban living labs have emerged as sites of experimental governance across a range of themes including the built environment, smart technologies, energy, and transportation systems. There is no agreed definition of experimentation in the literature, reflecting the diversity of conceptual frameworks and epistemological traditions. Transition scholars have conceptualised certain geographically bounded urban living labs as 'enclaves' to describe how experimentation takes place in niches that take advantage of spatial segregation to foster innovation under protected conditions (McCormick \& Hartmann, 2017). Design studies scholars frame experimentation through its capacity to democratise innovation using participatory approaches that foreground open-ended processes that invite wide collaboration with a multiplicity of stakeholders (Hillgren, Seravalli, \& Emilson, 2011). For some in city planning, 'trial-and-error urbanism' can lead to better planning outcomes (Dotson, 2016), while others acknowledge the creative logic of experimentation is at odds with the ethos of the public planning profession which prioritises the need to maintain "order, control and sta- bility in urban development" (Berglund-Snodgrass \& Mukhtar-Landgren, 2020, p. 103).

\subsection{Embedding}

Urban living labs are fundamentally characterised as embedded sites for exploring complex urban challenges and possible solutions where discrete sets of actors are empowered to address specific challenges at a more "manageable scale" (Voytenko et al., 2016, p. 47). The process of embedding is key to understanding experimentation in urban living labs and other transition arenas that are typically situated within a geographical area and tied to a particular local context that provides for a certain symbolic meaning or "sense of place" (van Steenbergen \& Frantzeskaki, 2018). According to von Wirth et al. (2019, p. 232), embedding involves the adoption of the "design, approach or outcomes" of experimentation into local structures or communities of practice. We define the process of embedding as anchoring urban experimentation in formal and informal institutions within a particular locale, with a view to potentially transform them to achieve intended sustainability outcomes (see Box 1 for empirical illustration). Institutions can refer to both place-specific (e.g., precinct development schemes) as well as sectoral institutions (such as energy or transport policies).

Examples of embedding from the literature include the Resilience Lab in Carnisse (Rotterdam), a four-year place-making experiment that was embedded in discourses of 'urban deprived neighbourhoods,' through which new place-meanings were developed related to community empowerment via a deep understanding of neighbourhood dynamics to build trust-based relationships (Frantzeskaki, van Steenbergen, \& Stedman, 2018). Manor House PACT, a three-year community-led project in London was embedded within a 'protected space' through partner organisation support which enabled the community to address local urban sustainability challenges through connections to food, green spaces, health, and employment within the context of seeking to build a 'green economy' (Astbury \& Bulkeley, 2018). Living Lab, The Neighborhood (Malmö), a transdisciplinary research lab initiated by researchers to empower migrant communities, was embedded in institutional contexts of fostering design for social innovation and the City of Malmö's ambition to become a 'knowledge city' and 'regional growth engine' (Cho, 2018). Challenges that we observe in the literature regarding embedding relate to the often short-term nature of urban living labs, enabled through project-based funding, which sits in contrast with the time needed for breaking into structural conditions underpinning conventional approaches to urban planning (Berglund-Snodgrass \& Mukhtar-Landgren, 2020).

The literature on urban experimentation reveals that embedding takes place through temporary alignment with existing organisational settings and structures (Raven et al., 2019). Embedding can be strengthened 
Box 1. Embedding the NZI.

The NZI is situated in Clayton, 20km south-east of Melbourne's central business district (CBD) and embedded within a number of education, health, research, and innovation agglomerations at a state and local level. The region surrounding Monash University is referred to as the Monash National Employment and Innovation Cluster (MNEIC), in the suburbs of Clayton and Huntingdale which supports approximately 75,000 jobs and contributes over $\$ 9.4$ billion to the Victorian economy each year (Victorian Planning Authority, 2017). At a local level, the MTP forms the core of the MNEIC cluster and has been identified as a Specialised Activity Centre and designated as a Technology Precinct in Metropolitan Melbourne (City of Monash, 2008). The MTP encompasses major institutions like Monash University, Monash Medical Centre and Children's Hospital, the future Victorian Heart Hospital, CSIRO, the Australian Synchrotron, and is home to various global business offices. The NZI is thus embedded within organisational visions and strategies of the university as well as in the MNEIC cluster planning framework as Victoria's leading non-CBD employment hub, and in the MTP under the state-based Plan Melbourne and Monash Planning Scheme, which zones land use under the MTP (Department of Environment, Land, Water and Planning, 2020).

We observe processes of anchoring in the NZI empirical illustration through interactions between actors that include Monash University, the Victorian Government, local councils, other research institutions, and major businesses that form part of the MTP. We interpret the NZI empirical illustration as a 'hybrid forum' or place where a variety of organisational actors can collaborate and undertake translation activities "that contribute to the durability of anchoring" the precinct living lab into existing and newly established or transformed institutional arrangements (Elzen et al., 2012, p. 15; Raven et al., 2019). By operationalising its main campus as a living lab within the MTP, the university is using the $\mathrm{NZI}$ to create an environment that enables "industry partnerships, research collaborations, and the development of technology prototypes" (Monash University, 2018). This focus on industry collaboration and technology development creates an opportunity for the NZI living lab to anchor net zero transformation within broader institutional settings and planning schemes related to employment, economic growth, innovation, place-making, and social development.

however through long-term processes of 'anchoring' when policy entrepreneurs and other institutional change agents create new links and rules between novel socio-technical innovations and existing institutions, in boundary-crossing forums between emerging niche contexts and an incumbent regime context (Elzen, van Mierlo, \& Leeuwis, 2012; Mintrom \& Luetjens, 2017; Smith \& Raven, 2012).

\subsection{Framing}

From transition studies we know that framing is an important process of experimentation that uses problem structuring, visioning, articulating expectations, storytelling, and narrating as strategic devices to orient and steer actors towards a desirable change trajectory (Loorbach, 2010; Nevens et al., 2013). According to transition scholars, narratives of change can have material consequences by working to reframe the action space of urban transformation and create opportunities to challenge dominant framings and institutions (Longhurst et al., 2016). Narratives of place can mobilise action and engender new opportunity contexts, social relations, and webs of meanings between actors undertaking local experiments (Frantzeskaki et al., 2018). We define framing as processes that situate the precinct-scale experiment in particular ways, by using stories and visions to foreground certain problems and propose specific actors, solutions, logics, or governance approaches in an attempt to influence the scope or direction of transformative pathways (see Box 2 for empirical illustration).
From the literature we observe that visioning was used in spatial planning projects like the urban living lab in the university town of Stellenbosch in South Africa. Stakeholders from the university and municipality including researchers, citizens, students, and professionals were enrolled in a participatory process culminating in the development of a draft spatial development framework around the vision of Stellenbosch as a "compact, inclusive and sustainable town" (Davies \& Swilling, 2018, p. 101). To contextualise transition experiments aimed at fighting climate change at the local level, a not-for-profit in Montréal worked with citizens to co-create desirable visions of the future to support community greening and the revitalisation of laneways within a neighbourhood setting (Audet et al., 2019). Challenges that we observe in the literature regarding framing include that top-down processes can bracket out collective visioning and democratic engagement as Levenda (2018) observes in relation to the Pecan Street smart grid test-bed in Austin, which worked with early adopters to implement a 'technological fix' that reduced the agency of participants to consumers and foreclosed possibilities for energy system change.

\subsection{Governing}

Experimentation is constituted by enabling transformative modes of urban governing, which refers to collaborative partnerships, mobilising resources, and orchestrating new institutional arrangements between diverse actors in the municipal, private sector, NGO, 
Box 2. Framing the NZI.

We observe three distinct visions related to framing the NZI: 1) net zero leadership; 2) innovation through partnerships; and 3) economic growth and job creation. Monash University was the first in Australia to commit to an energy reduction target and put forward an ambitious vision of "leading the way to a $100 \%$ renewable energy future" (Monash University, 2018). Monash is one of two Victorian universities in the Group of Eight (Go8), an elite network of the highest ranked research universities in Australia. As Australia's largest university and Go8 member, Monash has pursued a frontrunner position by showcasing its sustainability and market leadership in driving net zero transformation through commitments to decarbonising its four Australian campuses (ClimateWorks Australia, 2017). The 'net zero leadership' framing is significant because it emulates trailblazers like Stanford University (2019) which has transformed its campus into a living lab for sustainability and places Monash ahead of other Go8 competitor universities with similar plans to achieve carbon or energy neutrality. This leadership positioning also aligns with science-based targets and global policy commitments agreed to in the Paris Agreement to pursue a path towards reaching net zero $\mathrm{CO}_{2}$ emissions by the middle of this century to limit warming to $1.5^{\circ} \mathrm{C}$ (Intergovernmental Panel on Climate Change, 2018).

Monash University has developed a related "innovation through partnerships" vision for the MTP which capitalises on its sustainability credentials but foregrounds "connection," "deep partnerships" and "breaking down boundaries" as key goals (Sloan, 2018). This framing speaks to a desire to strengthen collaboration with major health, research, and innovation institutions in the precinct. The precinct itself is situated within the broader National Employment and Innovation Cluster, which planners have attempted to position as Melbourne's second CBD. The Victorian Planning Authority, a State Government statutory authority that reports to the Minister for Planning, has developed its own distinct vision for the MNEIC centred on economic growth and job creation through "place-making, transformative transport projects and urban renewal investment" to establish the cluster as a destination with "the highest job density outside of a capital city CBD in Australia" (Victorian Planning Authority, 2017, p. 4). This economic growth and job creation vision is a direct response to Melbourne's growing population which is projected to reach 10 million people by 2050 . These three distinct but related framings point towards a challenge in balancing the desire for a clear and shared framing about the future to guide planning, directionality, investments, and action, versus keeping multiple pathways open in light of navigating complex governance realities and future uncertainties.

and community sectors (Bulkeley \& Castán Broto, 2013; see Box 3 for empirical illustration). As mentioned, living labs are context dependent and embedded within specific institutional configurations, actor networks, and local governance structures (Raven et al., 2019). While experimentation offers potential for more participatory approaches to governing, it also runs the risk of main- taining the status quo depending on the purpose, which actors get to play a role, and whether intended goals are achieved (Hildén, Jordan, \& Huitema, 2017).

From the literature, we observe governing processes at play in the U-lab Bologna which saw the University and Municipality work together with students, the local community, and disadvantaged people

Box 3. Governing the NZI.

Governing of the NZI includes the development of a strategic roadmap as part of its 'Net Zero Emissions Strategy,' informed by initial analysis of net zero emissions pathways and long-term projection of baseline emissions. The roadmap recommends operational actions to achieve the net zero target including passive house standards for new buildings, and procurement criteria to encourage emerging technology pilots (ClimateWorks Australia, 2017). We observe characteristics of polycentric governance in the establishment of the NZI living lab whose steering group is comprised of academic and professional staff across research institutes, faculties, facilities management, and enterprise functions of the university. Polycentric governance can refer to decision-making across various levels whether spatial, modal, or domains of action (Jordan et al., 2015). Governance of the NZI living lab is coordinated by an interdisciplinary team of university staff at different levels across research, education, and operations. One challenge we observe is how to involve other actors in governing experimentation beyond the living lab at the broader scale of the MTP. The current governance of the NZI as a living lab for net zero precinct experimentation remains primarily an effort of a number of committed individuals within the university. We observe a need for intermediary actors with the potential to enable a broader shift towards a more distributed, long-term, and portfolio-focused approach to experimentation within the precinct. This could be pursued by establishing new institutional arrangements, and mobilising existing university-industry-policy relations, such as working collaboratively with the Victorian Planning Authority and City of Monash to harmonise net zero targets across the entire precinct via the Monash Planning Scheme. 
in co-design experiments for urban management in the care of public spaces. These actors were also enrolled in co-planning activities by helping to define the action plan for the broader district agenda with a view to ensuring greater accessibility of cultural heritage and public spaces (Gianfrate, Djalali, Turillazzi, Boulanger, \& Massari, 2020). Intermediaries can also play a significant role in urban experimentation and refer to NGOs, government or semi-government agencies that connect actors at different scales. Gustafsson and Mignon (2020) have shown how municipalities in Sweden used intermediation to translate international or national climate visions into local action through performing local experiments, task delegation, and creating coalitions in the context of local energy infrastructure.

Challenges that we observe in the literature regarding governing include the reproduction of existing structural inequalities through exclusion of community actors in experimentation whose lives are affected by the outcomes of smart city infrastructure upgrades (Evans \& Karvonen, 2014). Similarly, direct community engagement is sometimes lacking or pushed to the margins of smart-sustainable urban development where the impetus for change comes from municipal actors rather than pressure from civil society (Martin et al., 2019). State-led urban living labs have used top-down governance processes to undertake 'strategic experimentation' in line with national priorities. Smart Nansha, a smart city trial located in the Guangzhou Municipality of southern China, centred its governance around an "Industrial-Academic-Research Alliance" with regulators in the municipal or provisional government holding administrative power over membership and funding (Mai, 2018).

\subsection{Learning}

Learning is another key process of experimentation that actors in urban living labs and other arenas rely on to reveal a "variety of options" and to reframe "prob- lems and solutions" via interaction between stakeholders (Loorbach, 2010, p. 168). Urban living labs are social learning environments that require ongoing monitoring to understand the impacts of experimentation and evaluation of the results of activities in order to make adjustments based on iterative feedback (see Box 4 for empirical illustration). Social learning strives for change beyond the individual via interactions between actors through "communities of practice" (Reed et al., 2010, p. 4). As boundary objects, urban living labs can also facilitate reflexive learning by drawing on "constructive ambiguity" and "interpretive flexibility" to allow for openness to failure and knowledge co-creation (von Wirth, Frantzeskaki, \& Loorbach, 2020).

From the literature, we observe how the Livewell Yarra living lab, a low-carbon community trial in Melbourne, used social learning to empower residents to take actions to reduce carbon emissions at a personal, household, and community level through small group discussion, peer-support, and goal setting (Sharp \& Salter, 2017). Concept House Village Lab, a test-bed for sustainable building technologies in Rotterdam, reveals how situated learning can emerge through the participation of students and researchers in real-world contexts and how experimentation can become institutionalised by integrating lab-based courses into university curricula (von Wirth et al., 2019). Double-loop learning played a significant role in the eco-district of Western Harbour in Malmö by enabling planning departments to become "learning organisations" by acknowledging results, learning from mistakes, and reassessing strategies to adjust the course of action (Fitzgerald \& Lenhart, 2016, p. 376).

Challenges that we observe in the literature relate to how learning and translation in urban living labs can be more about contextualising transitions, such as the case with the Resilience Lab Carnisse, where the impact of experimentation related to "learning on what needs to change, how it can be changed and what one's own role is in this change process," rather than regime transformation (Frantzeskaki et al., 2018, p. 1057). Bulkeley

Box 4. Learning the NZI.

The NZI living lab is using learning to both undertake and evaluate experiments that will take place through various forms, including material interventions (e.g., on-site demonstrations), social or economic interventions (e.g., introducing probes and prototypes), or virtual interventions (e.g., through digital interactive design). The experiments will be focused on the three areas that together make up the majority of carbon emissions in Australian cities: energy, mobility, and buildings. Monitoring is critical for living labs and supports transition management processes by creating qualitative and quantitative measurements, communicating what has been learned through this to partners, stakeholders, and other participants, and enabling researchers to adjust the process as needed (Palgan, McCormick, \& Evans, 2018). In terms of the NZI living lab, the objects for monitoring include: 1) the precinct itself-metrics of decarbonisation, physical changes in the precinct, macro developments, and niche changes; 2 ) the actors involved in the living lab-their experiences and activities; 3 ) the living lab experiments-for new knowledge and insights about what works, when, and why (not); and 4) the overall transition process-its outputs, outcomes, and impacts, rate of progress, and barriers (Luederitz et al., 2017). The NZI must contend with coordination and facilitation challenges to enable learning and translation across multiple sectors (energy, mobility, and built environment) and long-term time-frames given the initiative's goal of university-wide decarbonisation by 2030 . 
et al. (2019, p. 334) make a similar point in relation to constrained experimentation where the focus tends to be on social or material reconfiguration within a building, district, or project with less emphasis on "translating the societal learning from such programmes into wider sustainability transitions."

\section{Discussion: Challenges and Implications for Future Research}

In this section we discuss key challenges and related implications of our analysis for future research on urban planning by experiment at precinct scale. A first observation we make is that following from our analysis, there is generally a need to better understand conceptually and practically how urban planning by experiment at the precinct scale is different from existing approaches to urban experimentation. In this article, we have reviewed the literature on urban experimentation to understand the state-of-the-art, but acknowledged that this literature is likely to be at the beginning of what experimentation at the precinct scale is. Hence, we deliberately started our investigation by positioning our framework of embedding, framing, governing, and learning in and through experimentation at precinct scale as tentative. To further articulate our framework, we draw inspiration from debates in the literature regarding project-based experimentation versus precinct-scale experimentation that aggregates across multiple projects, domains, and longer time-frames (Geels \& Raven, 2006; Torrens \& von Wirth, 2020). Table 1 provides a proposition of what sets precinct-scale experimentation aside from the current, often one-off-project-approach to urban experimentation. The main proposition that we propose is that urban planning by experiment at the precinct scale needs to consider experimentation as an ongoing effort across multiple projects, domains, and longer time-frames, implying that forms of embedding, framing,

Table 1. Processes of 'project-based' vs 'precinct-scale' urban planning by experiment.

\begin{tabular}{lll}
\hline Process category & Project-based urban planning by experiment & Precinct-scale urban planning by experiment \\
\hline Embedding & Refers to the processes and conditions that & Refers to a portfolio approach to experimentation \\
& enable a project to become spatially and & within a precinct, i.e., to the processes and conditions \\
institutionally anchored in a particular place & that embed continuous experimentation over longer \\
& and organisational setting, e.g., by aligning & time-frames in particularly territories and \\
the experiment temporarily with existing & organisational settings, e.g., through establishing a \\
& structures and procedures. & $\begin{array}{l}\text { dedicated place-based, intermediating actor/s that } \\
\text { coordinates experimentation across single projects, }\end{array}$ \\
& domains, and time-frames.
\end{tabular}

Framing Entails the articulation of narratives, visions, expectations, or discourses that enables the formulation and legitimation of a specific solution. Often narrowly referring to a particular societal challenge but not necessarily considering the experiment in relation to other challenges and solutions.

Governing Relates to bringing together a limited number of heterogenous actors in a project, providing a budget, developing a project plan, and executing the plan with fairly clear role division of actors involved.

Learning
Multi-dimensional and reflexive, but necessarily limited to specific issues, predefined through project plans, and limited budget availability. Learning is social but focussed on those involved in the project.
Entails a multi-domain, multi-challenge, and multi-solution articulation of narratives, visions, expectations, or discourses which considers the ambiguities, uncertainties, multiple pathways, futures, and problem definitions that are part and parcel of the precinct experience.

Strategically focussed, yet complex and ambiguous, requiring navigation of complex social and organisational settings, with fluid boundaries of who is involved (regularly changing actor constellations), and acknowledging the limited controllability of precinct planning processes (distributed and polycentric governance), drawing on strategic budgets as well as opportunistic resource opportunities as they emerge through actors coming in and out of the processes.

Strategically focussed, yet distributed and organic, requiring substantial coordination and facilitation to enable learning across multiple domains, initiatives, and long-term time-frames. Learning is inward and outward focussed, with a view to enable sharing lessons within the precinct, as well as translating, networking, and connecting them with initiatives and scales elsewhere. 
governing, and learning will be more emergent, distributed, dynamic, and ambiguous in nature. Future empirical and conceptual work could consider these features in more detail.

Second, we observe that experimentation through urban living labs still often takes place at the fringe of mainstream urban planning practices, can be short-term in nature (Sharp \& Salter, 2017), funded through temporary budgets (Greer, von Wirth, \& Loorbach, 2020), and driven by progressive urban actors in otherwise conventional planning regimes (Karvonen, Evans, \& van Heur, 2014). With such incentives and in such contexts, urban living labs are sometimes more interested in delivering short-term results and reconfiguring socio-material practices rather than shifting regimes (Bulkeley et al., 2019). Experimentation is indeed not a silver bullet to replace all current practices, but what this does suggest is that it requires a much better understanding of how experimentation relates to other, more mainstream techniques in urban planning, such as best-practice construction, urban modelling, or cost-benefit and risk analysis. We argue therefore that urban planning regimes themselves must transform in order to empower the practice of precinct-scale experimentation. For instance, if the notion of complete decarbonisation, as implied in the concept of 'net zero' is to become a reality, net zero thinking needs to become embedded in each and every aspect of urban planning, whether that is in the institutional frameworks driving urban planning, the risk investment tools that financial institutions use for financing urban infrastructures, or the strategic orientations of major providers of urban technologies such as buildings, roads, or energy systems. Despite that precincts are a common scale in urban planning practice, their net zero transformation depends on changes in the broader governance, decision-making, and power hierarchies across scales, public policy portfolios, and industrial sectors. A key question for a program of work on precinct-scale transitions is under which (political, social, economic, or otherwise) conditions precinct-scale change advocates are actually able to have significant impact (Doren, Runhaar, Raven, Giezen, \& Driessen, 2020). Cycling in Amsterdam, which was in decline in the 1970s, provides an example of how niche actors used urban experimentation through illegal bike lanes and pressure for greater community consultation to normalise mass cycling and radically transform the regulatory regime and physical space in that city (Savini \& Bertolini, 2019).

Third, the ability to integrate reflexivity, learning, and failure in urban planning experimentation remains a challenge, but is critical in processes of transformative innovation like the shift towards net zero emission cities (Turnheim \& Sovacool, 2020). City labs, for instance, occupy a boundary position that enable diverse stakeholders to trial urban planning by experiment with highly uncertain outcomes where: "There is potential for failure, but on the other hand, there is the potential to discover something highly innovative" (Scholl \& Kemp,
2016, p. 95). Nevertheless, political acceptance of failure remains difficult, and this might be even more challenging at precinct scale, as precincts might be perceived as 'too big to fail,' hence limiting the potential of learning and transformation. We also note that failure is not a black-and-white outcome of urban experimentation, but subject to interpretative flexibility (Bijker, 1987). While low-carbon city experiments might eventually not live up to their stated ambitions, unfulfilled promises (also known as failures) can yield important lessons to help drive future planning improvements, as a recent analysis of Masdar City makes clear (Griffiths \& Sovacool, 2020). A future research agenda could focus on understanding and unpacking relationships between experimentation, learning from failure, and political liability in a way that enables transformation rather than stagnation.

Fourth, we observe that community engagement is another important aspect of governing precinctscale experimentation and can support inclusion through diverse participation (Wiktorowicz et al., 2018). Maintaining a balance between top-down (Mai, 2018) and bottom-up (Gianfrate et al., 2020) participation remains difficult but important for enabling transparency, inclusiveness, and direct communication (den Hartog et al., 2018). Community engagement is often undertaken in instrumental ways in urban planning, but the creation of meaningful spaces for deliberation and learning about needs, desires, limitations, inequalities, etc. emerging from experimentation are normatively important, too. Recent work on green infrastructure projects in Europe suggests that citizen participation can shape shared commitment in early stages but that power imbalances between local authorities and community actors remains an ongoing challenge (Willems, Molenveld, Voorberg, \& Brinkman, 2020). Design-led interventions using participatory methods has the potential to democratise experimentation in urban planning yet evidence of its capacity to shape decision-making remains ambivalent (Nyseth et al., 2019). Future research could investigate how to further enrol community engagement in urban planning by experiment to democratise precinct-scale governance and help navigate the complex social realities at work at this scale. We specifically point towards the potential of exploring new cross-overs between urban experimentation and disciplines such as design anthropology that are concerned with understanding and creating tools for "how processes of renewal and change are lived, experienced and represented" (Pink, 2012, p. 2).

Finally, the multiplicity of frames, actor networks, and institutions at the level of a precinct makes urban experimentation challenging. The NZI empirical illustration reveals the complexity of embedding and framing within a socio-spatial context constituted by a university campus, technology precinct, and innovation cluster that sit within a broader planning scheme. Appreciating the multiplicity of urban infrastructures, schemes, framings, initiatives, solutions, and future visions at precinct scale 
can shed light on whether experimental processes and governance arrangements are fragmented and mutually hostile (competing), parallel and loosely-coupled (co-existing), or symbiotic and mutually-reinforcing (complementary; Hodson, Geels, \& McMeekin, 2017). Even within apparent singular socio-technical fields such as 'net zero' there is a high degree of diversity, uncertainty, and ambiguity in appraising what 'good looks like' in the future of the precinct. As warned elsewhere, caution must be taken to assume upfront objective status for the sustainability of particular experiments or solutions (Raven et al., 2017). There is a need for more research into how such necessary open-ended processes embracing multiplicity align with and challenge conventional planning processes organised around prediction, stability, and control.

\section{Conclusion}

This article identified four processual categories relevant to precinct-scale experimentation: embedding, framing, governing, and learning. We developed our discussion of results through a systematic literature review and an empirical illustration of the NZI, a living lab based at a university campus that is part of a broader technology precinct. We suggest a number of fruitful areas for future research including portfolio focussed approaches to urban planning by experiment, shifting of urban planning regimes, constraints on reflexive learning and failure, opportunities for greater community engagement, and embracing multiplicity in precinct-scale experimentation. We hope that this article contributes towards future scholarship on processes and challenges of urban planning by experiment and the role of precinct-scale experimentation within the broader portfolio of urban planning practices.

\section{Acknowledgments}

We would like to thank Mr Scott Ferraro, Program Director of the Monash Net Zero Initiative, for feedback and reflections on earlier versions of the manuscript.

\section{Conflict of Interests}

The authors declare no conflict of interests.

\section{References}

Astbury, J., \& Bulkeley, H. (2018). Bringing urban living labs to communities: Enabling processes of transformation. In S. Marvin, H. Bulkeley, L. Mai, K. McCormick, \& Y. V. Palgan (Eds.), Urban living labs: Experimenting with city futures (pp. 106-125). London and New York, NY: Routledge.

Audet, R., Segers, I., \& Manon, M. (2019). Experimenting the sustainability transition in Montreal laneways The Nos milieux de vie! Case Study. Canadian Journal of Urban Research, 28(2), 46-57.

Berglund-Snodgrass, L., \& Mukhtar-Landgren, D. (2020). Conceptualizing testbed planning: Urban planning in the intersection between experimental and public sector logics. Urban Planning, 5(1), 96-106.

Bijker, W. E. (1987). The social construction of Bakelite: Toward a theory of invention. In W. E. Bijker, T. P. Hughes, \& T. J. Pinch (Eds.), The social construction of technological systems: New directions in the sociology and history of technology (pp. 159-187). Cambridge, MA: MIT Press.

Bulkeley, H., \& Castán Broto, V. (2013). Government by experiment? Global cities and the governing of climate change. Transactions of the Institute of British Geographers, 38(3), 361-375.

Bulkeley, H., Coenen, L., Frantzeskaki, N., Hartmann, C., Kronsell, A., Mai, L., \& Palgan, Y. V. (2016). Urban living labs: Governing urban sustainability transitions. Current Opinion in Environmental Sustainability, 22, 13-17.

Bulkeley, H., Marvin, S., Palgan, Y. V., McCormick, K., Breitfuss-Loidl, M., Mai, L., \& Frantzeskaki, N. (2019). Urban living laboratories: Conducting the experimental city? European Urban and Regional Studies, 26(4), 317-335.

Cho, E. J. (2018). Transforming a neighborhood into a living laboratory for urban social innovation: A comparative case study of urban living labs. In P. L. Rau (Ed.), International conference on cross-cultural design (pp. 275-285). Cham: Springer.

City of Monash. (2008). Urban design guidelines: Monash Technology Precinct (Monash Specialised Activity Centre). Melbourne: City of Monash. Retrieved from https://www.monash.vic.gov.au/ files/assets/public/building-amp-planning/planningpermits-amp-applcations/other-guidelines/urbandesign-monash-technology-precinct-guidelines.pdf

ClimateWorks Australia. (2017). Net zero emissions strategy: Monash University (Unpublished report). Melbourne: ClimateWorks Australia.

Davies, M., \& Swilling, M. (2018). Intermediation and learning in Stellenbosch's urban living lab. In S. Marvin, H. Bulkeley, L. Mai, K. McCormick, \& Y. V. Palgan (Eds.), Urban living labs: Experimenting with city futures (pp. 91-105). London and New York, NY: Routledge.

Department of Environment, Land, Water and Planning. (2020). Monash planning scheme. Melbourne: Department of Environment, Land, Water and Planning. Retrieved from https://planningschemes.delwp.vic.gov.au/schemes/monash

den Hartog, H., Sengers, F., Xu, Y., Xie, L., Jiang, P., \& de Jong, M. (2018). Low-carbon promises and realities: Lessons from three socio-technical experiments in Shanghai. Journal of Cleaner Production, 181, 692-702.

Doren, D., Runhaar, H., Raven, R. P. J. M., Giezen, M., \& Driessen, P. (2020). Institutional work in diverse 
niche contexts: The case of low-carbon housing in the Netherlands. Environmental Innovation and Societal Transitions, 35, 116-134.

Dotson, T. (2016). Trial-and-error urbanism: Addressing obduracy, uncertainty and complexity in urban planning and design. Journal of Urbanism: International Research on Placemaking and Urban Sustainability, 9(2), 148-165.

Elzen, B., van Mierlo, B., \& Leeuwis, C. (2012). Anchoring of innovations: Assessing Dutch efforts to harvest energy from glasshouses. Environmental Innovation and Societal Transitions, 5, 1-18.

Evans, J., \& Karvonen, A. (2014). 'Give me a laboratory and I will lower your carbon footprint!': Urban laboratories and the governance of low-carbon futures. International Journal of Urban and Regional Research, 38(2), 413-430.

Evans, J., Karvonen, A., \& Raven, R. P. J. M. (Eds.). (2016). The experimental city. London: Routledge.

Fitzgerald, J., \& Lenhart, J. (2016). Eco-districts: Can they accelerate urban climate planning? Environment and Planning C: Government and Policy, 34(2), 364-380.

Frantzeskaki, N., van Steenbergen, F., \& Stedman, R. C. (2018). Sense of place and experimentation in urban sustainability transitions: The Resilience Lab in Carnisse, Rotterdam, The Netherlands. Sustainability Science, 13(4), 1045-1059.

Geels, F. W., \& Raven, R. P. J. M. (2006). Non-linearity and expectations in niche-development trajectories: Ups and downs in Dutch biogas development (1973-2003). Technology Analysis \& Strategic Management, 18(3/4), 375-392.

Gianfrate, V., Djalali, A., Turillazzi, B., Boulanger, S. O., \& Massari, M. (2020). Action-research towards a circular urban system for multi-level regeneration in historical cities: The case of Bologna. International Journal of Design \& Nature and Ecodynamics, 15(1), 5-11.

Greer, R., von Wirth, T., \& Loorbach, D. (2020). The diffusion of circular services: Transforming the Dutch catering sector. Journal of Cleaner Production, 267, 121906.

Griffiths, S., \& Sovacool, B. K. (2020). Rethinking the future low-carbon city: Carbon neutrality, green design, and sustainability tensions in the making of Masdar City. Energy Research \& Social Science, 62, 101368.

Grodal, S., Anteby, M., \& Holm, A. L. (2020). Achieving rigor in qualitative analysis: The role of active categorization in theory building. Academy of Management Review. Advance online publication.

Gustafsson, S., \& Mignon, I. (2020). Municipalities as intermediaries for the design and local implementation of climate visions. European Planning Studies, 28(6), 1161-1182.

Hildén, M., Jordan, A., \& Huitema, D. (2017). Special issue on experimentation for climate change solutions editorial: The search for climate change and sustainabil- ity solutions-The promise and the pitfalls of experimentation. Journal of Cleaner Production, 169, 1-7.

Hillgren, P. A., Seravalli, A., \& Emilson, A. (2011). Prototyping and infrastructuring in design for social innovation. CoDesign, 7(3/4), 169-183.

Hodson, M., Geels, F. W., \& McMeekin, A. (2017). Reconfiguring urban sustainability transitions, analysing multiplicity. Sustainability, 9(2), 299.

Honey-Rosés, J. (2019). A review of field experiments in planning and urban research. Planning Practice \& Research, 34(5), 558-572.

Intergovernmental Panel on Climate Change. (2018). Summary for policymakers. In V. Masson-Delmotte, P. Zhai, H.-O Pörtner, D. Roberts, J. Skea, P. R. Shukla, ... T. Waterfield (Eds.), Global warming of $1.5^{\circ} \mathrm{C}$ : An IPCC special report on the impacts of global warming of $1.5^{\circ} \mathrm{C}$ above pre-industrial levels and related global greenhouse gas emission pathways, in the context of strengthening the global response to the threat of climate change, sustainable development, and efforts to eradicate poverty. Geneva: World Meteorological Organization.

Jordan, A. J., Huitema, D., Hildén, M., van Asselt, H., Rayner, T. J., Schoenefeld, J. J., \& Boasson, E. L. (2015). Emergence of polycentric climate governance and its future prospects. Nature Climate Change, 5(11), 977-982.

Karvonen, A., Evans, J., \& van Heur, B. (2014). The politics of urban experiments: Radical change or business as usual? In S. Marvin \& M. Hodson (Eds.), After sustainable cities (pp. 104-115). London: Routledge.

Kemp, R., \& Loorbach, D. (2006). Transition management: A reflexive governance approach. In J. P. Voss, D. Bauknecht, \& R. Kemp (Eds.), Reflexive governance for sustainable development (pp. 103-130). Cheltenham and Northampton, MA: Edward Elgar.

Kemp, R., Schot, J., \& Hoogma, R. (1998). Regime shifts to sustainability through processes of niche formation: The approach of strategic niche management. Technology Analysis \& Strategic Management, 10(2), 175-195.

Khorasany, M., Azuatalam, D., Glasgow, R., Liebman, A., \& Razzaghi, R. (2020). Transactive energy market for energy management in microgrids: The Monash Microgrid case study. Energies, 13(8), 2010.

Kiss, B., van der Jagt, A. P. N., Dorst, H., Bulkeley, H., McCormick, K., \& Raven, R. P. J. M. (2020). Greening infrastructures through urban experimentation: Exploring the politics of nature-based solutions. Manuscript in preparation.

Levenda, A. M. (2018). Urban living labs for the smart grid: Experimentation, governmentality and urban energy transitions. In S. Marvin, H. Bulkeley, L. Mai, K. McCormick, \& Y. V. Palgan (Eds.), Urban living labs: Experimenting with city futures (pp. 52-73). London and New York, NY: Routledge.

Liedtke, C., Welfens, M. J., Rohn, H., \& Nordmann, J. (2012). LIVING LAB: User-driven innovation for sus- 
tainability. International Journal of Sustainability in Higher Education, 13(2).

Longhurst, N., Avelino, F., Wittmayer, J., Weaver, P., Dumitru, A., Hielscher, S., \& Elle, M. (2016). Experimenting with alternative economies: Four emergent counter-narratives of urban economic development. Current Opinion in Environmental Sustainability, 22, 69-74.

Loorbach, D. (2010). Transition management for sustainable development: A prescriptive, complexity-based governance framework. Governance, 23(1), 161-183.

Luederitz, C., Schäpke, N., Wiek, A., Lang, D. J., Bergmann, M., Bos, J. J., \& Farrelly, M. A. (2017). Learning through evaluation: A tentative evaluative scheme for sustainability transition experiments. Journal of Cleaner Production, 169, 61-76.

Mai, L. (2018). Placing sustainability in communities: Emerging urban living labs in China. In S. Marvin, $\mathrm{H}$. Bulkeley, L. Mai, K. McCormick, \& Y. V. Palgan (Eds.), Urban living labs: Experimenting with city futures (pp. 210-230). London and New York, NY: Routledge.

Martin, C., Evans, J., Karvonen, A., Paskaleva, K., Yang, D., \& Linjordet, T. (2019). Smart-sustainability: A new urban fix? Sustainable Cities and Society, 45, 640-648.

Marvin, S., Bulkeley, H., Mai, L., McCormick, K., \& Palgan, Y. V. (Eds.). (2018). Urban living labs: Experimenting with city futures. London and New York, NY: Routledge.

McCormick, K., \& Hartmann, C. (Eds.). (2017). The emerging landscape of urban living labs: Characteristics, practices and examples. Rotterdam and Vienna: Governance of Urban Sustainability Transitions (GUST) and Urban Europe.

McLean, A., Bulkeley, H., \& Crang, M. (2016). Negotiating the urban smart grid: Socio-technical experimentation in the city of Austin. Urban Studies, 53(15), 3246-3263.

Mintrom, M., \& Luetjens, J. (2017). Policy entrepreneurs and problem framing: The case of climate change. Environment and Planning C: Politics and Space, 35(8), 1362-1377.

Monash University. (2018). The Net Zero initiative. Clayton: Monash University. Retrieved from https:// www.monash.edu/_data/assets/pdf_file/0020/ 1140365/Monash-Net-Zero-Brochure.pdf

Mongeon, P., \& Paul-Hus, A. (2016). The journal coverage of Web of Science and Scopus: A comparative analysis. Scientometrics, 106(1), 213-228.

Nevens, F., Frantzeskaki, N., Gorissen, L., \& Loorbach, D. (2013). Urban transition labs: Co-creating transformative action for sustainable cities. Journal of Cleaner Production, 50, 111-122.

Nyseth, T., Ringholm, T., \& Agger, A. (2019). Innovative forms of citizen participation at the fringe of the formal planning system. Urban Planning, 4(1), 7-18.

Palgan, Y. V., McCormick, K., \& Evans, J. (2018). Urban living labs: Catalysing low carbon and sustainable cities in Europe? In S. Marvin, H. Bulkeley, L. Mai, K. McCormick, \& Y. V. Palgan (Eds.), Urban living labs: Experimenting with city futures (pp. 21-36). London and New York, NY: Routledge.

Pink, S. (2012). Situating everyday life: Practices and places. London: SAGE Publications.

Puerari, E., De Koning, J. I., von Wirth, T., Karré, P. M., Mulder, I. J., \& Loorbach, D. A. (2018). Co-creation dynamics in urban living labs. Sustainability, 10(6), 1893.

Raven, R. P. J. M., Ghosh, B., Wieczorek, A., Striling, A., Ghosh, D., Jolly, S., . . Sengers, F. (2017). Unpacking sustainabilities in diverse transition contexts: Solar photovoltaic and urban mobility experiments in India and Thailand. Sustainability Science, 12(4), 579-596.

Raven, R. P. J. M., Sengers, F., Spaeth, P., Xie, L., Cheshmehzangi, A., \& de Jong, M. (2019). Urban experimentation and institutional arrangements. European Planning Studies, 27(2), 258-281.

Reed, M. S., Evely, A. C., Cundill, G., Fazey, I., Glass, J., Laing, A., \& Stringer, L. C. (2010). What is social learning? Ecology and Society, 15(4).

Savini, F., \& Bertolini, L. (2019). Urban experimentation as a politics of niches. Environment and Planning $A$ : Economy and Space, 51(4), 831-848.

Scholl, C., \& Kemp, R. (2016). City labs as vehicles for innovation in urban planning processes. Urban Planning, 1(4), 89-102.

Seyfang, G., \& Smith, A. (2007). Grassroots innovations for sustainable development: Towards a new research and policy agenda. Environmental Politics, 16(4), 584-603.

Sharp, D., \& Salter, R. (2017). Direct impacts of an urban living lab from the participants' perspective: Livewell Yarra. Sustainability, 9(10), 1699.

Sloan, K. (2018). The Monash Precinct: Joining the dots to build for the future. Monash Lens. Retrieved from https://lens.monash.edu/@global-leaders-week/ 2018/09/18/1360337/monash-precinct-a-visionfor-the-future

Smith, A., \& Raven, R. P. J. M. (2012). What is protective space? Reconsidering niches in transitions to sustainability. Research Policy, 41(6), 1025-1036.

Stanford University. (2019). University as a living lab. Sustainable Stanford. Retrieved from https:// sustainable.stanford.edu/campus-action/universityliving-lab

Torrens, J., \& von Wirth, T. (2020). Strategies for redressing projectification in urban experimentation: On portfolios and ecologies. In Proceedings of the 11th International Sustainability Transition Conference Governance in an Era of Change: Making Sustainability Transitions Happen (pp. 2941-2959). Vienna: Vienna University of Economics and Business and Austrian Institute of Technology.

Turnheim, B., \& Sovacool, B. K. (2020). Exploring the role of failure in socio-technical transitions research. Envi- 
ronmental Innovation and Societal Transitions, 37, 267-289.

United Nations Framework Convention on Climate Change. (2020). Race to Zero campaign. United Nations Framework Convention on Climate Change. Retrieved from https://unfccc.int/climate-action/ race-to-zero-campaign\#eq-1

van den Bosch, S. (2010). Transition experiments: Exploring societal changes towards sustainability (Doctoral dissertation). Rotterdam: Erasmus University Rotterdam.

van Steenbergen, F., \& Frantzeskaki, N. (2018). The importance of place for urban transition experiments: Understanding the embeddedness of urban living labs. In S. Marvin, H. Bulkeley, L. Mai, K. McCormick, \& Y. V. Palgan (Eds.), Urban living labs: Experimenting with city futures (pp. 231-247). London and New York, NY: Routledge.

Victorian Planning Authority. (2017). Monash national employment and innovation cluster: Draft framework plan (March 2017). Melbourne: Victorian Planning Authority. Retrieved from https://vpa-web. s3.amazonaws.com/wp-content/uploads/2017/03/ Monash-NEIC-framework-plan_March2017_WEB.pdf von Wirth, T., Frantzeskaki, N., \& Loorbach, D. (2020). Urban living labs as inter-boundary spaces for sustainability transitions? In G. de Roo, C. Yamu, \& C. Zuidema (Eds.), Handbook on planning and complexity (pp. 237-257). Cheltenham: Edward Elgar Publishing.

von Wirth, T., Fuenfschilling, L., Frantzeskaki, N., \& Coenen, L. (2019). Impacts of urban living labs on sustainability transitions: Mechanisms and strategies for systemic change through experimentation. European Planning Studies, 27(2), 229-257.

Voytenko, Y., McCormick, K., Evans, J., \& Schliwa, G. (2016). Urban living labs for sustainability and low carbon cities in Europe: Towards a research agenda. Journal of Cleaner Production, 123, 45-54.

Wiktorowicz, J., Babaeff, T., Breadsell, J., Byrne, J., Eggleston, J., \& Newman, P. (2018). WGV: An Australian urban precinct case study to demonstrate the $1.5 \mathrm{C}$ agenda including multiple SDGs. Urban Planning, $3(2), 64-81$.

Willems, J. J., Molenveld, A., Voorberg, W., \& Brinkman, G. (2020). Diverging ambitions and instruments for citizen participation across different stages in green infrastructure projects. Urban Planning, 5(1), 22-32.

\section{About the Authors}

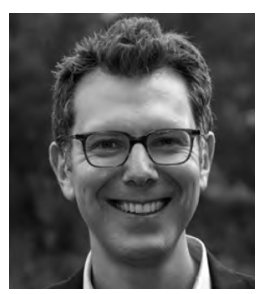

Darren Sharp (PhD) is a Research Fellow at Monash Sustainable Development Institute where he is Research Coordinator of Net Zero Precincts: an interdisciplinary approach to decarbonising cities. Darren is a sustainability transitions researcher interested in urban experimentation, living labs, multistakeholder governance, grassroots innovations, and the sharing economy. His research speaks to the possibilities of social learning, institutional arrangements, community agency, and new urban imaginaries to drive the transformation of cities towards sustainability.

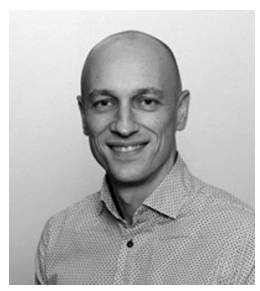

Rob Raven is an Interdisciplinary Scholar, Professor of Sustainability Transitions, and Deputy Director (research) at Monash Sustainable Development Institute. He is also Visiting Professor at the Copernicus Institute of Sustainable Development at Utrecht University. His interest is in understanding the dynamics and governance of sustainability transitions and socio-technical innovation. His current research agenda is focused on analysis of transformative change in urban context such as smart and sustainable cities. A key question is how socio-technical experimentation, institutional change, and incumbency in urban regimes co-produce sustainable city futures. 